\title{
Numerical Studies of BPF Pressure Pulsation in Centrifugal Ventilators
}

\author{
Sergey Timushev \\ Rocket Engine, Moscow Aviation Institute (National Research University), Moscow, Russia \\ Email: irico@mai.ru
}

How to cite this paper: Timushev, S. (2019) Numerical Studies of BPF Pressure Pulsation in Centrifugal Ventilators. Journal of Applied Mathematics and Physics, 7, 32013215.

https://doi.org/10.4236/jamp.2019.712225

Received: November 28, 2019 Accepted: December 19, 2019 Published: December 26, 2019

\begin{abstract}
There is a link between pressure pulsations in the centrifugal ventilator working cavity and its noise level on blade passing frequencies (BPF). They result from non-stationary hydrodynamic interaction between the impeller flow and volute casing. Pressure pulsations depend on quality of hydraulic profiling of ventilator. The amplification of pressure pulsations can happen due to matching of frequencies of oscillations with acoustic resonance frequencies. In ventilators the length of acoustic waves can be comparable to the size of the casing. Therefore, the variation of rotation speed, number of rotor blades, the fan installation in the ventilation system can substantially modify amplitudes of pressure pulsations due to the resonance inside the ventilator cavity. Various numerical studies of BPF pressure pulsation in ventilators are undertaken using the method and software package based on a representation of non-stationary motion of a compressible medium as a superposition of acoustic and vortex modes. In this case non-linear equations for unsteady vortex motion of an incompressible liquid are solved with a bigger time step. Wave equation relative to the pressure pulsations considering acoustic impedances on the borders of computational domain is solved by an explicit method. As a result, the whole processor time for both modes of oscillations is reduced and accuracy of prediction for the acoustical mode is improved.
\end{abstract}

\section{Keywords}

Centrifugal Fan, Pump, Pulsations, Noise Spectra, BPF, Acoustic-Vortex Equation

\section{Review of the Problem}

Noise reduction in order to minimize its negative impact on human activity in the open space, residential, office and industrial premises, cultural and religious 
institutions, salons of cars, trains, aircraft and spacecraft cabins, is becoming an increasingly urgent task, since this significantly affects both human health and productivity. These issues are receiving increasing attention in developed countries, which is reflected in the significant tightening of noise control requirements in accordance with ISO standards [1] [2]. Numerical simulation of the acoustics of cooling fans of computer devices is becoming an important modern engineering problem [3], as well as for train fans [4] and for fans of modern air conditioning and purification systems.

As is known, the main sources of centrifugal fan noise are mechanical or hydrodynamic in nature. Identification of sources of mechanical nature and methods of their elimination are analyzed in detail in domestic and foreign literature [5] [6] [7]. Experimental studies of fans and pumps show common features of the phenomenon in both type of blade machines and have established [8], that hydrodynamic sources give the main contribution to noise emission. The experience of experimental works shows a direct relationship between pressure pulsations in the fan or pump flow cavity and its vibro-noise characteristics [9]. Noise and vibration of the hydrodynamic nature is caused by the peculiarities of the working fluid flow in the flow part of the fan or pump [10] [11]: unsteady interaction of the flow leaving the impeller with the discharge device; vortex formation, including small-scale turbulence and large-scale vortex structures (back flow); cavitation processes in the flow part of the pumps.

The spectral composition of pressure, noise and vibration pulsations in fans and pumps is represented by a broadband background and pronounced discrete components, which can be especially dangerous when coinciding with the intrinsic resonant frequencies of structural elements or when the rotor and stator blades are not optimally combined.

As already noted above, unsteady hydrodynamic phenomena in the flow part of the fan, depending on the causes contributing to their occurrence, can be divided into three types:

The first-arising as a result of hydrodynamic interaction of the flow outgoing the impeller with the fan discharge device. The second-vortex, caused by the vortex nature of the fluid flow [12]: small-scale turbulence in the boundary layer and the formation of large-scale vortex structures, back flows under non-rated modes of operation and inhomogeneous velocity field at the inlet or outlet of the blade machine [13] [14]. Studies of the flow in centrifugal fans with different blade geometries are covered in [15] [16]. Detailed studies of the flow parameters in centrifugal compressors [17] [18] [19] and the flow in absolute and relative motion at the impeller outlet of centrifugal pumps confirm that the flow in the blade channel and at the outlet of the centrifugal impeller can be divided into two areas-a high-energy jet and a low-energy wake zone [20] [21]. This character of the flow determines a significant nonuniformity in the pitch of the blade cascade of relative and absolute velocities and angles of flow, since the low-energy zone is adjacent to the suction side of the blade. A particularly sharp change in flow parameters occurs near the inlet edges of the guide vanes and in 
the volute tongue [22]. Therefore, such great attention is paid to the choice of the optimal radial gap between the impeller and the guide-vane device or the tongue of the volute [23] [24]. As a rule, the amplitude of the total signal of pressure pulsations is minimal near the optimal flow mode of operation [25] and increases significantly at flow rates that is less or more than the optimal one. In several works it is shown that amplitudes of the low-frequency components of the spectrum increase under low-flowrate modes. In over-flowrate modes, pressure pulsations increase due to the separation of the flow and on the guide vanes or near the throat section of the volute. When the flow rate increases, the total level of pressure pulsations can also increase due to an increase in the amplitudes of discrete components at the blade passing frequency (BPF) and its harmonics [26]. The specified features of change of pressure pulsations depending on the flow rate are characteristic for different points of a flow-path of centrifugal pumps. Pressure pulsations were investigated at the inlet to the pumps, in the channels of the centrifugal impeller, at the outlet of the centrifugal impeller, in blade-less diffusers, in the guiding vane channels, in volutes. The first computational model is proposed by Ioffe-Panchenko [27] —in this model, the vibration at the BPF and its harmonics is caused by unsteady forces acting on the guide vanes. For the first time, a computational model for determining the amplitudes of BPF pressure pulsations in a centrifugal pump collector with guide vanes was proposed by Chen [26]. These results can be obtained in a simpler way from the analysis of only phase relations for pressure pulses. In the approximation of the potential two-dimensional flow of an ideal fluid, the problem was solved in the study of Sukup. Various semi-empirical methods for prediction of the amplitude of pressure pulsations at the outlet of a centrifugal pump on the operating parameters and design factors have been developed. With the development of computational fluid dynamics methods, methods for computation pressure pulsations in blade machines were developed based on solving the equations of hydromechanics. D. Croba et al. proposed a method for calculating the unsteady two-dimensional flow in a centrifugal impeller and a volute based on the solution of the averaged Navier-Stokes equations and the k- $\varepsilon$ turbulence model [28] [29].

Another approach using Reynolds equations is proposed in S. Chu and coauthors [30]. The unsteady pressure in the volute outlet is obtained by integrating the Reynolds equation, where all terms dependent on the velocity field are determined experimentally by the laser-anemometric method.

A similar approach is developed in the work of M. S. Thompson with co-authors [31], where laser-anemometry data are also used, but pressure pulsations are calculated by solving the Blokhintsev-Howe equation [32] with respect to the stagnation enthalpy.

Currently existing approaches to fan noise modeling are based mainly on the application of the Lighthill equation [33]. Further, the work of Curle [34], FlowcsWilliams and Hawkings [35] formulated a theoretical basis for the development of methods for calculation the aerodynamic noise of blade machines on the basis 
of the so-called aeroacoustic analogy, as well as the application of the Kirchhhoff's theorem [36].

As is known, in blade machines, where the Mach number of the circumferential velocity at the periphery of the rotor is below 0.5 , noise emission occurs mainly by the dipole source type. Aeroacoustic analogy introduces a certain simplification of the physical processes of noise generation in order to describe them analytically. The dipole nature of the radiation is due to the pressure forces acting on the rotor and stator blades from the gas flow. These forces, stationary or unsteady, are the cause of the tonal BPF noise and its higher harmonics, which is generated by the rotor blades, as well as, as a result of the rotor-stator interaction, the guide vanes of the stator. The analytical formulation of these processes is based on the formalization proposed by Sears [37], and represents the emitted sound in the form of so-called spiral modes [38]. Although Tyler and Sofrin [39] have shown that at low values of the Mach number of the relative flow, spiral modes exponentially decay in a long pipe, this does not exclude their propagation at high wave numbers of the inhomogeneity of the flow. Additional analysis is also required for the case of rotor radiation in open space. In the case of rotor-stator interaction, the application of spiral mode cut-off conditions for a subsonic fan does not agree with experimental data [40], which may be due to such an important additional source of BPF noise generation as the stationary inhomogeneity of the flow at the rotor inlet.

In connection with the development of CFD and CAA methods, approaches based on numerical modeling of unsteady flow in blade machines by modern CFD and subsequent determination of acoustic radiation [41] [42] are increasingly developed. In combination with aeroacoustics analogy [43], other methods are developed, such as RANS-LEE-SNGR [44], and DDES [45] together with the Lighthill or Ribner equation implementation [46].

Physical mechanisms of generation of aerodynamic noise of axial and centrifugal fans discussed in detail in the book by A. Guedel [47]. He pointed out that fan noise consists of tonal component and broadband noise. Tonal components at BPF usually dominates the spectrum and determines the overall level of sound power.

\section{Method}

\subsection{Definition and Assumptions}

The method is based on the solution of the boundary value problem for Fourier transformed convective wave equation in complex variables in the Cartesian coordinate system in an arbitrary region with boundary conditions in the complex impedance form. The noise source is given in the form of sound power on the surface near the rotor, limiting the zone of vortex disturbances [48] (pseudo-sound). Sound power is determined by the solution of acoustic-vortex wave equation. In the acoustic-vortex method, the noise source is represented as a local derivative of the vortex mode pressure. This determines the source, pressure 
pulsations and noise propagation in the near field as a direct result of numerical simulation.

Studies of the dynamic parameters of pumps, fans show that the maximum amplitudes in the spectra of pressure pulsations and vibration in the design modes have discrete components at the BPF

$$
f_{b}=k z_{1} f_{r} \text {. }
$$

where

$f_{r}$ is the rotor frequency speed, $\mathrm{Hz}$;

$z_{1}$ is number of blades of the centrifugal impeller;

$k$ is the harmonic number.

In the development of a physical and mathematical model of pulsating flow in a blade machine with subsonic flow one must consider the nonlinear nature of the oscillation generation process and the acoustic nature of its propagation in the working path of the machine.

Let's make the following assumptions:

- Subsonic flow;

- Isentropic flow;

- Viscous diffusion is neglected;

- Acoustic oscillations (velocities of acoustic motion due to the compressibility of medium) are small in comparison with vortex oscillations (velocities of swirl and the translational motion of a fluid as an incompressible medium).

\subsection{Equations}

For the velocity of the fluid, dividing the motion into vortex and acoustic modes, one obtains the following expression ( $\varphi$-is the acoustic potential, $\mathrm{U}$ is the velocity of the vortex mode):

$$
\mathbf{V}=\mathbf{U}+\nabla \varphi=\mathbf{U}+\mathbf{V}_{\mathbf{a}}
$$

With the introduction of dimensionless variables, using as scales the radius, circumferential speed and the period of passage of the impeller blades

$$
\tilde{\mathbf{r}}=\mathbf{r} / R_{2} ; \tilde{\mathbf{U}}=\mathbf{U} / u_{2} ; \tau=\left(t u_{2} z_{1}\right) /\left(2 \pi R_{2}\right) ; \tilde{i}=i / u_{2}^{2}
$$

from the basic equations of motion of the compressible medium after a series of transformations, neglecting convection part of derivative, one obtains the acoustic-vortex equation

$$
\Lambda^{2} \frac{\partial^{2} h}{\partial \tau^{2}}-\tilde{\Delta} h=-\tilde{\Delta} g
$$

The dimensionless similarity criterion of this problem is the ratio of the radius of the impeller to the wavelength of BPF:

$$
\Lambda=R_{2} / \lambda
$$

The amplitude of the pressure oscillations is usually an order of magnitude lower than the average undisturbed pressure, so for the oscillations of the re- 
duced enthalpy it is possible to write approximately

$$
h=\tilde{i}-\tilde{i}_{0} \approx\left(P-P_{0}\right) /\left(\rho_{0} u_{2}^{2}\right)=P^{\prime} /\left(\rho_{0} u_{2}^{2}\right)
$$

The pressure fluctuations in the working fluid are equal to the sum of the oscillations caused by unsteady vortex motion of the medium as incompressible"pseudo-sound" and by acoustic oscillations (acoustic mode).

$$
g \approx\left(P_{v}-P_{0}\right) / \rho u_{2}^{2}=P_{v}^{\prime} / \rho u_{2}^{2}
$$

Here $P$ is the pressure in the compressible medium, $i_{0}, P_{0}, \rho_{0}$ is the average enthalpy, pressure and density. The function $g$ corresponds to pseudo-sound pressure pulsations $\left(P_{V}-P_{0}\right)$ for a vortex mode motion.

The right part in the wave Equation (4) is determined from the solution of the equations of motion of the vortex mode (incompressible medium), from which follows

$$
-\Delta P_{v}=\nabla\left[\nabla\left(U^{2} / 2\right)-\nabla \times(\nabla \times \mathbf{U})\right]
$$

Thus, the solution of the problem is divided into two main stages: 1) solving the equations of motion for an incompressible medium, determining the source function, non-stationary boundary conditions for the vortex mode and 2) solving the inhomogeneous wave equation with respect to pressure pulsations.

Using the local complex impedance $Z$, the boundary condition for the acoustic mode can be represented in the form

$$
\frac{\partial\left(h_{k}-g_{k}\right)}{\partial n}=-\left(\Lambda k / Z_{k}\right)\left(\frac{\partial\left(h_{k}-g_{k}\right)}{\partial \tau}\right)
$$

where $k-B P F$ harmonic number, $n-$ normal to the boundary surface.

\section{Validation and Prediction}

To verify the correct functioning of the developed software, calculations of pressure pulsation amplitudes in several pumps and fans were carried out.

\subsection{Air Pump Model}

Detailed testing of the software package was carried out on a unique experimental setup [49], where pressure pulsations in the model centrifugal pump were measured at more than 300 points in the impeller and volute (Figure 1).

This made it possible to reconstruct the pressure field and the amplitude field of spectral components in the entire working cavity of the model pump. In the calculations, a sufficiently detailed finite-difference grid was used to identify all the features of the unsteady flow- 12 grid nodes were placed on the inter-blade pitch. It should be noted that this pump does not have an outlet pipeline, the working fluid is air. The complex specific acoustic impedance at the outlet of pump volute diffuser was set considering this condition.

As shown by calculations and experiment, pressure pulsations in the discharge device of the pump have a complex spectral composition and differ in amplitude and phase at different points of the volute. The first three harmonics 


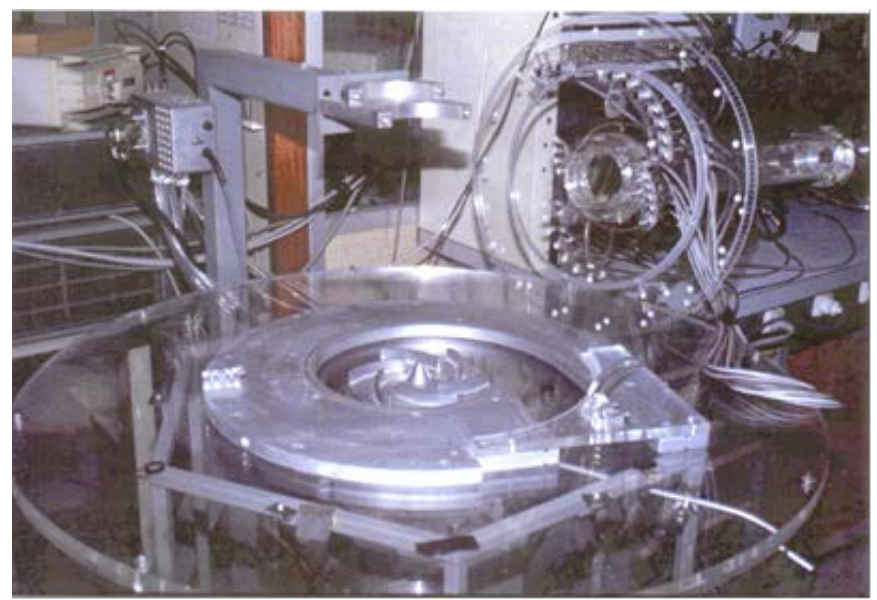

Figure 1. Model air pump.

of the frequency of the blades were decisive in the spectrum of oscillations (the calculation was carried out for seven harmonics). Considering this condition.

The largest amplitudes are obtained in the region adjacent to the tongue of the volute and at the impeller outlet. At the outlet of the pump diffuser there is a region of low amplitudes due to the influence of the exit boundary condition ("open end"). In addition, inside the volute there is a zone of relatively low amplitudes associated with the peculiarities of generation and propagation of pseudo-sound pressure pulsations in the centrifugal pump volute.

In Figure 2 the comparison of experimental and calculated data on the total amplitude of the signal of pressure pulsations at different points of the volute is shown. In the calculation of "MK1", the flow in the impeller is assumed to be stationary. The calculation of "MK3" accounts the unsteady flow in the centrifugal impeller, when the flow parameters in the blade channels depend on the angular position of the impeller relative to the volute tongue. One can note good match of measurement results and calculations as it is shown in Figure 3.

\section{2. $\Lambda$-Effect}

This method has been successfully used in modeling the influence of radial clearance, optimizing the geometry of centrifugal impeller, determining the favorable ratio of the number of blades of the impeller and the blade diffuser. The $3 \mathrm{D}$ computing version is currently being tested for use in blade machines such as axial and diagonal pumps and fans, lawn mowers, UAV propellers and wind turbines.

Figure 4 and Figure 5 show the distribution of the amplitudes of the 1st BPF harmonic in different fans. Both blade machines have a simple volute, but the parameter $\Lambda$ is 10 times different. In addition, in the industrial fan (Figure 5) the relative size of the vortex disturbances is much smaller due to the large number of centrifugal impeller blades. At a small value $\Lambda$ (Figure 4) pressure pulsations in a large part of the volute are formed by pseudo-sound disturbances having higher amplitudes. 


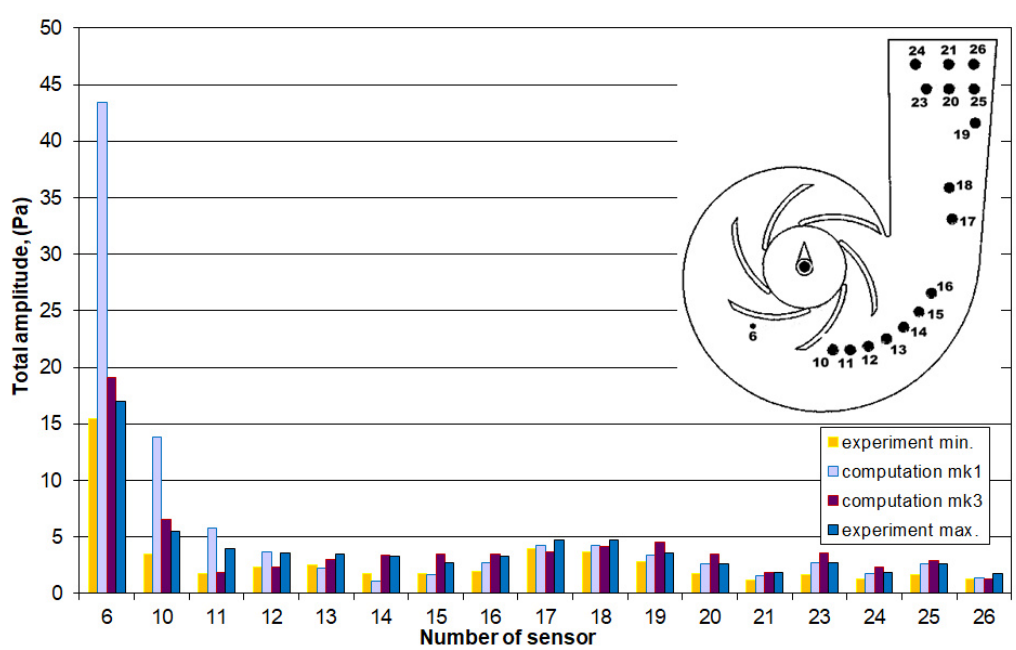

Figure 2. Comparison of calculated and measured total amplitude $(\mathrm{Pa})$ at different points.
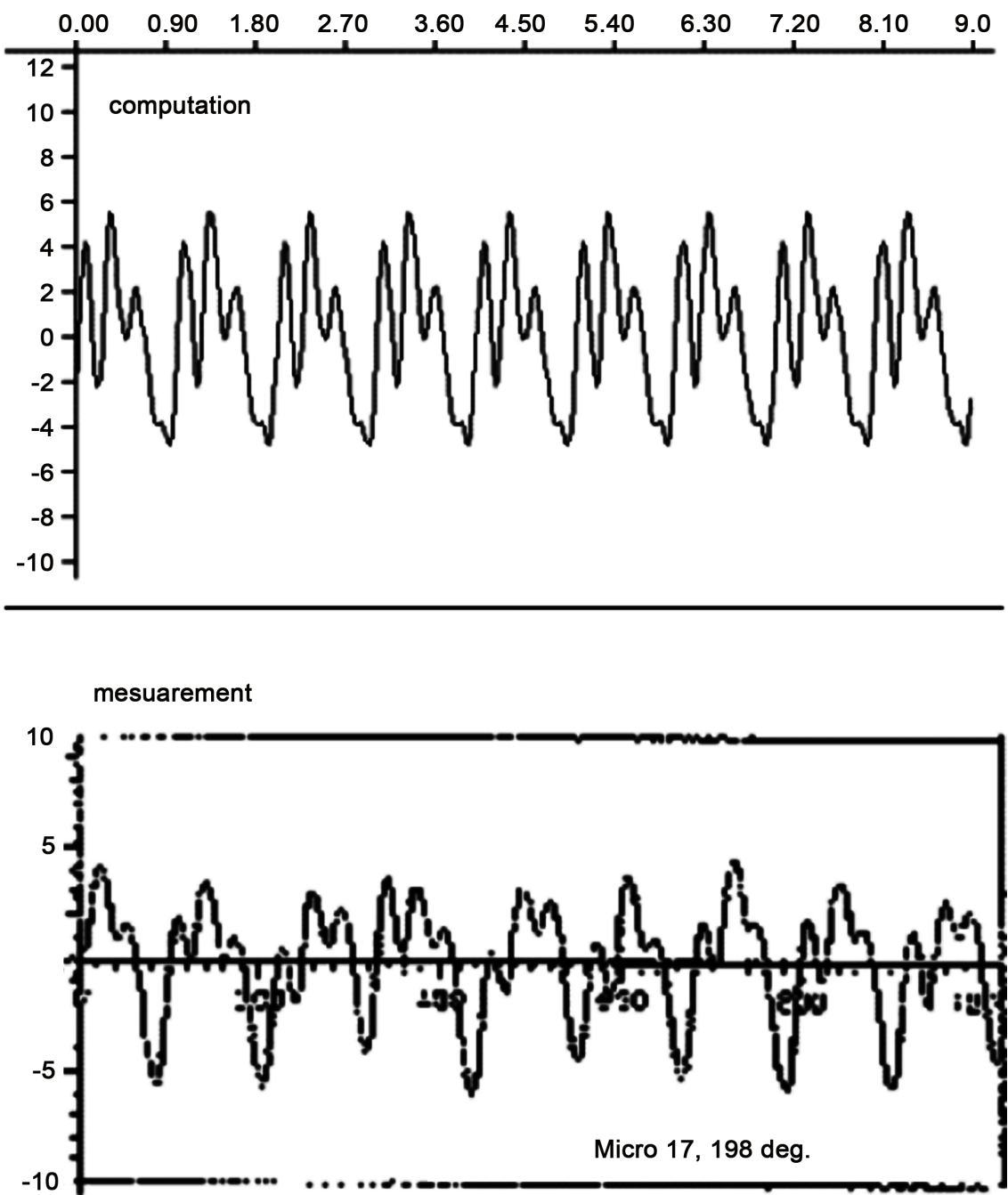

Figure 3. The calculated (top) and experimental (bottom) signal of the sensor 17 (see Figure 2). 


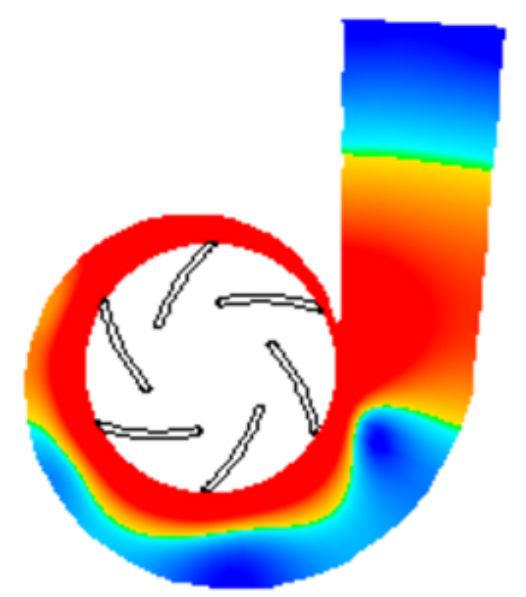

Figure 4. Amplitude distribution of the 1st BPF harmonic; simple volute; $\Lambda=0.04$.

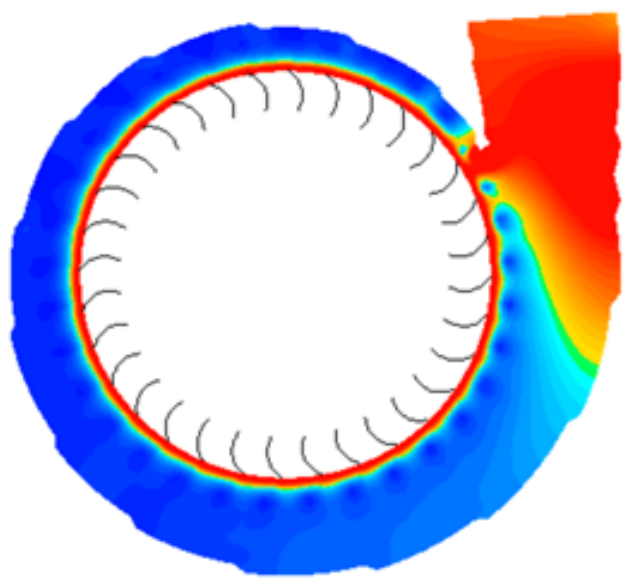

Figure 5. Amplitude distribution of the 1st BPF harmonic; simple volute; $\Lambda=0.37$.

In an industrial fan, the zone of high amplitudes is located only in the immediate vicinity of the outlet of the centrifugal impeller, and the rest of the volute is occupied by acoustic waves.

The calculation of pressure pulsations in a model air pump with the vane diffuser shows that the BPF pressure pulsations strongly depend on the interference of acoustic waves coming out of different channels of the vane diffuser.

Thus, the maximum amplitude (Figure 6) is fixed in the most part of the volute and outlet part of diffuser channels.

\subsection{Radial Gap Effect}

The radial clearance between the centrifugal impeller and the volute tongue is the most important parameter affecting the pressure pulsations in centrifugal type blade machines.

The calculated study of the radial clearance effect is based on the geometry of an industrial centrifugal pump tested in CETIM (Nantes, France). The pump has a $173 \mathrm{~mm}$ diameter centrifugal impeller with 5 blades. The calculated operating mode of $1200 \mathrm{rpm}$ with a flow rate of $0.066 \mathrm{~m}^{3} / \mathrm{s}$ is considered. Three alteration 


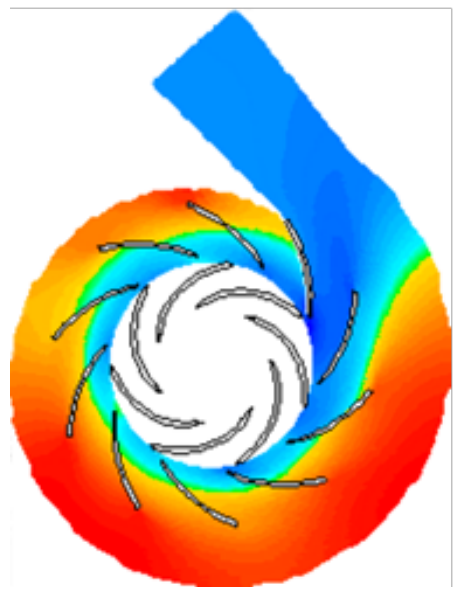

Figure 6. Amplitude distribution of the 1 st BPF harmonic; blade diffuser; $\Lambda=0.14$.

of the volute are considered, as shown in Figure 7: 1-radial clearance 7\% (existing geometry), 2 and 3-radial clearance $11 \%$. In case 2 the radial clearance change is performed without deterioration of the geometry-all geometric parameters of the conic diffuser and the volute tongue are kept unchanged. In case 3 , a radial clearance of $11 \%$ is obtained by cutting the tongue and this changes the pressure pulsation signal with increasing the second BPF harmonic.

\subsection{D Method}

The three-dimensional model is based on the same assumptions as previous $2 \mathrm{D}$ method.

This allows one to deduce the acoustic-vortex equation with respect to the enthalpy pulsations insubsonic isentropic flow of the compressible medium.

$$
\frac{1}{a^{2}} \frac{\partial^{2} i}{\partial t^{2}}-\Delta i=\nabla\left(\nabla \left(\frac{1}{2} U^{2}-\mathbf{U} \times(\nabla \times \mathbf{U})\right.\right.
$$

Defined in this way, amplitude fluctuations of the enthalpy will include pseudo-sound pulsations and acoustic waves.

The right part of the wave Equation (9) is determined from the velocity field of the vortex mode obtained by the three-dimensional method of computational fluid dynamics [48] [50] based on the Navier-Stokes(RANS)equations

$$
\frac{\partial \mathbf{U}}{\partial t}+\nabla(\mathbf{U} \otimes \mathbf{U})=-\frac{\nabla P}{\rho}+\frac{1}{\rho} \nabla\left(\left(\mu+\mu_{t}\right)\left(\nabla \mathbf{U}+(\nabla \mathbf{U})^{T}\right)+\mathbf{F}\right.
$$

considering the continuity equation for the vortex mode of motion

$$
\begin{gathered}
\nabla \mathbf{U}=0 \\
\mu_{t}=C_{\mu} \rho \frac{k^{2}}{\varepsilon}
\end{gathered}
$$

Relation (13) determines the turbulent viscosity based on the standard $k-\mathcal{E}$ turbulence model.

The Navier-Stokes equations are solved by splitting method using an implicit scheme and high-order approximation for convective terms on a rectangular 


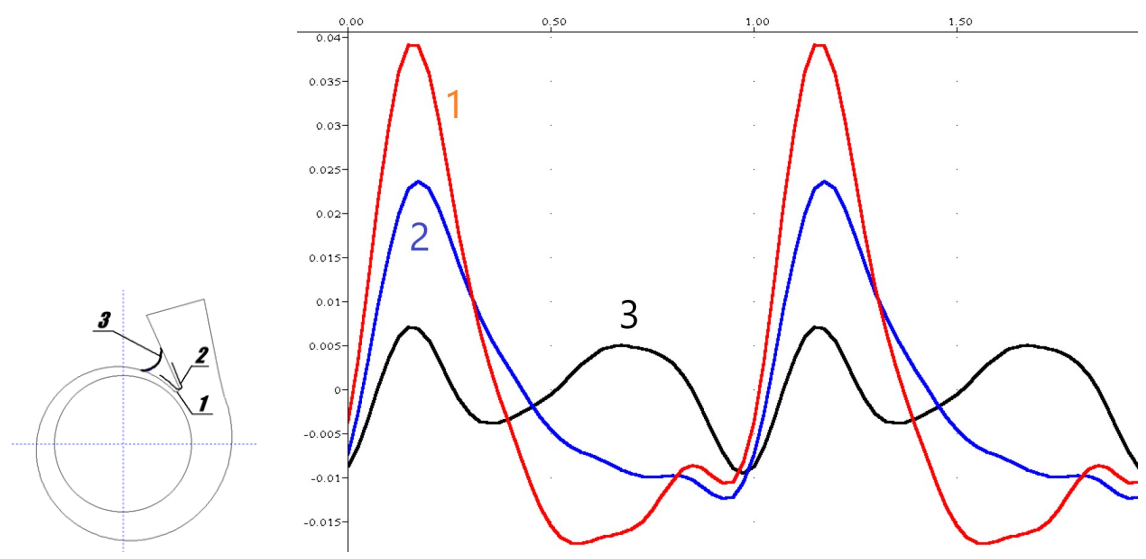

Figure 7. Left: radial clearance: $1-7 \%, 2-11 \%, 3-$ cut to $11 \%$; Right: $\bar{P}^{\prime}=P^{\prime} /\left(\rho \cdot U_{2}^{2}\right)$ reduced pressure pulsation on the tongue versus reduced time $\tau$.

grid that adapts to curvilinear boundaries-the initial grid boundary cells intersected by the boundary (e.g., the surface of the blade) are broken into arbitrary polyhedra, which provide a conservative record of the finite-volume equations of hydrodynamics, which ensures high accuracy of the solution even with a relatively small number of nodes of the computational grid. The initial approximation is zero pressure and velocity in the computational domain. The initial values for the kinetic energy and turbulence dissipation rate are calculated automatically on the first iteration. The boundary condition on the wall is the numerical equivalent of the logarithmic law for the velocity component tangent to the wall.

Using the local acoustic impedance $Z_{k}$, the boundary condition for the $k$-BPF harmonic enthalpy oscillations can be represented in the form

$$
\frac{\partial\left(i_{k}-I_{k}\right)}{\partial n}=-\frac{k}{a Z_{k}} \frac{\partial\left(i_{k}-I_{k}\right)}{\partial t}
$$

To test the acoustic-vortex method, pressure pulsations were measured before and behind the rotor of an axial fan VN-2, installed in a pipe with a diameter of $150 \mathrm{~mm}$ and a length of $940 \mathrm{~mm}$.

The fan has 5 working blades with a radius of $60 \mathrm{~mm}$. The fan casing with a diameter of $128 \mathrm{~mm}$ is installed in the pipe on movable supports to study the influence of boundary conditions on pressure pulsations and emitted noise. Four cross-shaped ribs are installed at the outlet in the fan stator (Figure 8).

The results given correspond to the position of the fan in the middle of the pipe. The measurements were performed at different radii and at different rotation speeds of the rotor.

The results of the measurements are compared with the calculation for the rotor speed of $2670 \mathrm{rpm}$, where the first BPF harmonic $222 \mathrm{~Hz}$ is significantly higher than the resonant frequency $168 \mathrm{~Hz}$ of the longitudinal mode of oscillations in the pipe determined experimentally. The position of the microphone was changed discretely in increments of $5-50 \mathrm{~mm}$. The signal was recorded in portions of $3 \mathrm{~s}$ with a sampling frequency of $10,000 \mathrm{~Hz}$ and processed in portions 


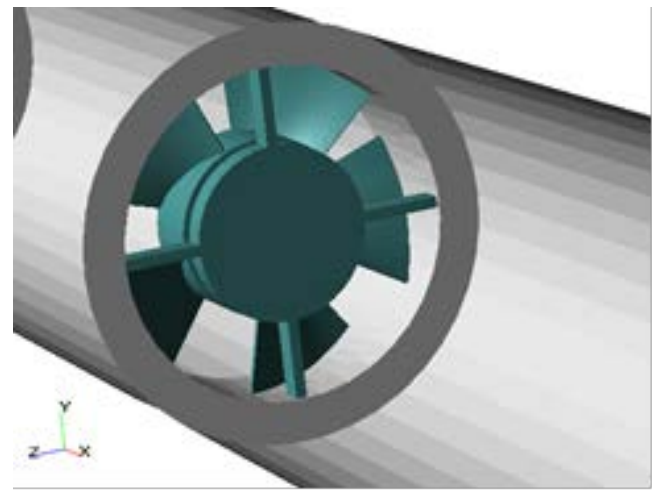

Figure 8. Fan installation sketch.

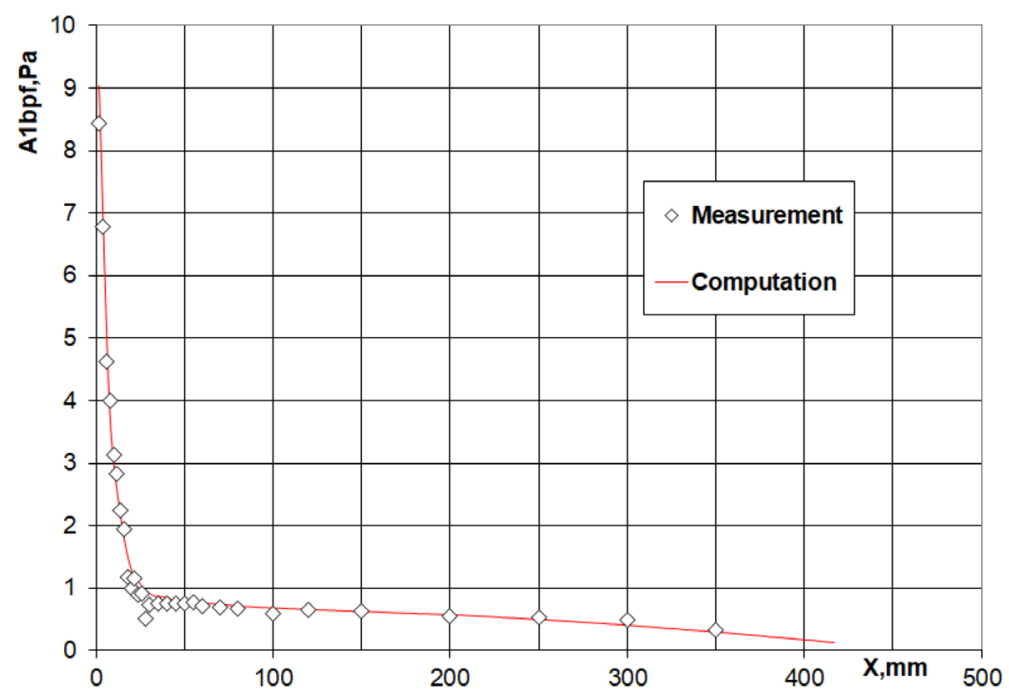

Figure 9. Amplitude of the first BPF harmonic on a radius of $60 \mathrm{~mm}$.

of $0.6 \mathrm{c}$ without overlap. The number of points of the spectrum is taken equal to 4096, the spectrum was smoothed by the Henning window. The frequency resolution in this case was $2441 \mathrm{~Hz}$. As the output values, the average amplitude of the BPF first harmonic was used for five portions of the signal recording.

The result of comparison of calculated and measured amplitudes of the first BPF harmonic in the input section of the pipe is presented in Figure 9. The plot shows the calculated curve and experimental points, as well as the amplitudes considering the standard deviation $s$. The calculated data are well consistent almost along the entire length of the input pipe section. A slight deviation is observed in the zone of $20-30 \mathrm{~mm}$ from the input edges of the blades, where the amplitude distribution is unstable due to interference of pseudo-sound pulsations and acoustic waves.

\section{Conflicts of Interest}

The author declares no conflicts of interest regarding the publication of this paper. 


\section{References}

[1] ISO 3740-1980 Acoustics-Determination of Sound Power Levels of Noise SourcesGuidelines for the Use of Basic Standards and for the Preparation of Noise Test Codes.

[2] ISO 11690-1 (1996) Acoustics-Recommended Practice for the Design of LowNoise Workplaces Containing Machinery-Part 1: Noise-Control Strategies.

[3] Thimany, J. (2014) Attacking Noise Early. Mechanical Engineering, 8, 44-49. https://doi.org/10.1115/1.2014-Dec-1

[4] Jiang, Y., Åbom, M., Feng, L.P., Timouchev, S. and Maliczak, C. (2007) Investigation of Sound Generation from an Axial Fan for Engine Cooling. Proceedings of 3 rd International Symposium on Fan Noise, 19-21 September 2007, Lyon.

[5] Vibration of Energy Machines. In: Grigoriev, N.V., Ed., Mashinostroenie, Moscow, 1974. (In Russian)

[6] Meyer, R.J. (1978) Solving the Problem of Vertical Puump Vibration. Pumps, Pompes, Pumpen, No. 141. (Translation No. 13-29073. М.: ВЦП, 1980).

[7] Vibrations in Technique. In: Chelomey, V.N., Ed., Mashinostroenie, Moscow, 1974. (In Russian)

[8] Suverina, N.N. and Solomakhova, T.S. (1982) On Calculation of Acoustic Characteristics of Radial Ventilators. Increasing of Efficiency of Ventilation Facilities. Moscow. (In Russian)

[9] Offenhguser (1973) Pressure Fluctuation Measurements on Centrifugal Pumps with Guide Vanes. VDI-Berichte, No. 193. (In German)

[10] Pokrovsky, B.V. and Yudin, E..Ya. (1966) Main Features of Noise and Vibration of Centrifugal Pumps. Acoustical Journal. (In Russian)

[11] Borovsky, B.I., Ershov, N.S., Ovsyannikov, B.V., et al. (1975) High Speed Bladed Pumps. Mashinostroenie, Moscow. (In Russian)

[12] (1977) Handbook of Turbulence. Volume 1 Fundamentals and Applications. In: Frost, W. and Moulden, T.H., Eds., Springer, Boston, MA.

[13] Fraser, W.N., Kasassik, I.J. and Bush, A.R. (1977) Study of Pump Pulsation, Surge and Vibration Throws Light on Reliability vs Efficiency. Power.

[14] Fraser, W.N. (1982) Recirculation in Centrifugal Pumps. World Pumps, No. 5.

[15] Lokshin, I.L. (1959) Study of Outlet Flow of Ventilator Centrifugal Impellers in Relative Motion. Industrial Aerodynamics. Moscow, TSAGI, Oborongiz. (In Russian)

[16] Raj, D. and Swim, W.B. (1981) Measurements of the Mean Flow Velocity and Velocity Fluctuations at the Exit of an FC Centrifugal Fan Rotor. ASME Journal of Engineering for Power, 103, 393-399. https://doi.org/10.1115/1.3230733

[17] Seleznev, K.P. and Galerkin, Yu.B. (1982) Centrifugal Compressors. Leningrad, Mashinostroenie. (In Russian)

[18] Eckardt, D. (1975) Instantaneous Measurements in the Jet-Wake Discharge Flow of a Centrifugal Compressor Impeller. J. Eng. Power, 97, 337-345. https://doi.org/10.1115/1.3445999

[19] Johnson, M.W. and Moore, J. (1980) The Development of Wake Flow in a Centrifugal Impeller. J. Eng. Power, 102, 382. https://doi.org/10.1115/1.3230265

[20] Johnston, J.P., Halleen, R.M. and Lezius, D.K. (1972) Effects of Spanwise Rotation on the Structure of Two-Dimensional Fully Developed Turbulent Channel Flow. Journal of Fluid Mechanics, 56, 533. https://doi.org/10.1017/S0022112072002502 
[21] Wagner, R.E. and Velkoff, H.R. (1972) Measurement of Secondary Flows in a Rotating Duct. ASME Journal of Engineering for Power, 94, 261-270. https://doi.org/10.1115/1.3445681

[22] Izmailov, R.A., Karadji, V.G., Solomakhova, T.S. et al. (1982) Influence of the Spiral Casing Tongue on Aero-Acoustic Characteristics of Rarial Ventilators. Increasing of Efficiency of Ventilation Facilities, Moscow. (In Russian)

[23] Bunjes, J.S. (1981) Diffuser or Volute Pump? A Comparison of Perfomances: Fluid Machinery for the Oil, Petrochemical and Related Industries. Eur. Congr. The Hague, 24-26 March 1981, London: Mech. Eng. Publ., 1981.

[24] Fraser, W.H., Karassik, I.J. and Bush, A.R. (1977) Study of Pump Pulsation, Surge and Vibration Throws Light on Reliability vs Efficiency. Power.

[25] Pitkanen, R. (1979) Pressure Fluctuations in Centrifugal Pumps. Pumps-PompesPumpen, No. 156.

[26] Chen, Y.N. (1961) Water-Pressure Oscillations in the Vlute Casings of Storage Pumps. Sulzer Technical Review.

[27] Ioffe, R.L. and Panchenko, V.I. (1972) Study of the Effect of Blade Numbers of Hydraulic Machines on Their Vibroacoustic Characteristics. Mashinovedenie. (In Russian)

[28] Croba, D. and Kueny, J.L. (1992) Unsteady Flow Computation in a Centrifugal Pump Coupling of the Impeller and the Volute. Fan Noise. An International INCE Symposium, Senlis.

[29] Croba, D., Kueny, J.L., Hureau, F. and Kermarec, J. (1993) Numerical and Experimental Unsteady Flow Analysis in Centrifugal Pumps. Impeller and Volute Interaction. Pump Noise and Vibrations. 1 st International Symposium, Clamart.

[30] Chu, S., Dong, R. and Katz, J. (1993) The Effect of Blade-Tongue Interactions on the Flow Structure, Pressure Fluctuations and Noise within a Centrifugal Pump. Pump Noise and Vibrations. 1 st International Symposium, Clamart.

[31] Thompson, M.C., Hourigan, K. and Stokes, A.N. Prediction of the Noise Generation in a Centrifugal Fan by Solution of the Acoustic Wave Equation.

[32] Howe, M.S. (1975) Contribution to the Theory of Aerodynamic Sound, with Application to Excess Jet Noise and the Theory of the Flute. J. Fluid Mech, 71, 625-673. https://doi.org/10.1017/S0022112075002777

[33] Lighthill, M.J. (1952) On Sound Generated Aerodynamically. Part I. General Theory. Proceedings of the Royal Society, London, 564-587. https://doi.org/10.1098/rspa.1952.0060

[34] Curle, N. (1955) The Influence of Solid Boundaries upon Aerodynamic Sound. Proc. Royal Soc. A 231, 505-514. https://doi.org/10.1098/rspa.1955.0191

[35] Flowcs-Williams, J.E. and Hawkings, D.L. (1969) Sound Generation by Turbulence and Surfaces in Arbitrary Motion. Philosophical Transactions of the Royal Society A264, 321-342. https://doi.org/10.1098/rsta.1969.0031

[36] Farassat, F. and Myers, M.K. (1988) Extension of Kirchhhoff's Formula to Radiation from Moving Surfaces. Journal of Sound and Vibration, 123, 451-461. https://doi.org/10.1016/S0022-460X(88)80162-7

[37] Sears, W.R. (1941) Some Aspects of Non-Stationary Airfoil Theory and Its Practical Application. Journal of the Aeronautical Sciences, 8. https://doi.org/10.2514/8.10655

[38] Atassi, H. and Hamad, G. (1981) Sound Generated in a Cascade by Three-Dimensional Disturbances Convected in a Subsonic Flow. Report NASA AIAA-81-2046. 
https://doi.org/10.2514/6.1981-2046

[39] Tyler, J.M. and Sofrin, T.G. (1962) Axial Flow Compressor Noise Studies. SAE Trans., 70, 309-332. https://doi.org/10.4271/620532

[40] Goldstain, M.E. (1976) Aeroacoustics. McGraw Hill, New York. (Mashinostroenie, Moscow, 1981)

[41] Caro, S. and Moreau, S. (2001) Low-Speed Fan Noise. Proceedings of the Symposium, Ecole Centrale de Lyon, 8-9 November 2001. (In French)

[42] Caro, S., Sandboge, R., Iyer, J. and Nishio, Y. (2007) Presentation of a CAA Formulation Based on Lighthill's Analogy for Fan Noise. Proceedings of 3 rd International symposium on Fan Noise, Lyon, 19-21 September 2007.

[43] Sandboge, R., Washburn, K. and Peak, C. (2007) Validation of a CAA Formulation Based on Lighthill's Analogy for a Cooling Fan and Mower Blade Noise. Proceedings of 3rd International symposium on Fan Noise, Lyon, 19-21 September 2007.

[44] Zhu, Y.J., Ou, Y.H. and Tian, J. (2008) Experimental and Numerical Investigation on Noise of Rotor Blade Passing Outlet Grille. NCEJ. https://doi.org/10.3397/1.2949901

[45] De Silouane, R., Nicolas, Z. and Andrew, H. (2019) Use OpenFOAM Coupled with Finite and Boundary Element Formulations for Computational Aero-Acoustics for Ducted Obstacles. Inter Noise.

[46] Ribner, H.S. (1964) The Generation of Sound by Turbulent Jets. Advances in Applied Mechanics, 8, 103-182. https://doi.org/10.1016/S0065-2156(08)70354-5

[47] Guédel, A. (1999) Acoustics of Ventilators. CETIAT. PYC LIVRES. (In French)

[48] Aksenov, A.A., Gavrilyuk, V.N. and Timushev, S.F. (2016) Numerical Simulation of Tonal Fan Noise of Computers and Air Conditioning Systems. Acoustical Physics, 62, 447-455. https://doi.org/10.1134/S1063771016040011

[49] Tourret, J., et al. (1991) Hydraulic Noise Generation Studies in Centrifugal Turbomachine through Visualization of the Non Stationary Pressure Field in the Volute and in the Impeller. ASME/Reprinted from FED, Vol. 128, Experimental and $\mathrm{Nu}-$ merical Flow Visualization, In: Khalighi, B., et al., Eds., Book No. 1991, 239-246.

[50] Timouchev, S., Tourret, J., Pavic, G. and Aksenov, A. (2006) Numerical 2-D and 3-D Methods for Computation of Internal Unsteady Pressure Field and Near-Field Noise of Fans. Noise Control Engineering Journal, 54, 15-20. https://doi.org/10.3397/1.2888774 